\title{
Memantine Augmentation Improves Symptoms in Serotonin Reuptake Inhibitor-Refractory Obsessive-Compulsive Disorder: A Randomized Controlled Trial
}

\section{Authors}

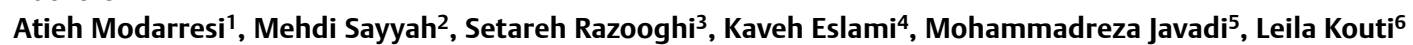

\section{Affiliations}

1 Research Center for Rational Use of Drugs, Tehran University of Medical Sciences, Tehran, Iran

2 Education Development Center, Ahvaz Jundishapur University of Medical Sciences, Ahvaz, Iran

3 Student Research Committee, Ahvaz Jundishapur University of Medical Sciences, Ahvaz, Iran

4 School of Pharmacy, Ahvaz Jundishapur University of Medical Sciences, Ahvaz, Iran

5 Clinical Pharmacy Department, Faculty of Pharmacy and Research Center for Rational Use of Drugs, Tehran University of Medical Sciences, Tehran, Iran

6 School of Pharmacy, Ahvaz Jundishapur University of Medical Sciences, Ahvaz, Iran

$\begin{array}{lr}\text { received } & 14.08 .2017 \\ \text { revised } & 16.09 .2017 \\ \text { accepted } & 19.09 .2017\end{array}$

\section{Bibliography}

DOI https://doi.org/10.1055/s-0043-120268

Published online: 3.11.2017

Pharmacopsychiatry 2018; 51: 263-269

(c) Georg Thieme Verlag KG Stuttgart · New York

ISSN 0176-3679

\section{Correspondence}

Leila Kouti

Golestan Blvd

Ahvaz

Khouzestan, Iran

Ikouti.pharmacotherapy@gmail.com

\begin{abstract}
Introduction There is a large body of evidence on the clinical benefits of augmentation therapy with glutamate-modulating agents, such as memantine in reducing OCD symptoms.

Methods A double-blind, placebo-controlled trial was conducted on SRIrefractory OCD patients. Thirty-two patients were randomized to receive either $20 \mathrm{mg} /$ day memantine or placebo augmentation and were visited at baseline and every 4 weeks for 12 weeks. Results were measured using the YaleBrown Obsessive-Compulsive Scale (Y-BOCS).

Results The Y-BOCS total score was significantly reduced in the memantine group at the end of weeks 8 and 12, while no improvement was observed in the placebo group throughout the trial. A reduction of $40.9 \%$ in the mean Y-BOCS total score by week 12 in the memantine group resulted in $73.3 \%$ of patients achieving treatment response. The findings showed that a time to effect of 8 weeks was necessary to observe significant improvement in OCD symptoms, while treatment response was only seen after 12 weeks of memantine augmentation.

Discussion Memantine is an effective and well-tolerated augmentation in severe OCD patients refractory to SRI monotherapy.
\end{abstract}

\section{Introduction}

Obsessive-compulsive disorder (OCD) is the fourth common neuropsychiatric disorder worldwide and is a major risk for serious social disability and morbidity $[1,2]$. Serotonin reuptake inhibitors (SRIs) and cognitive behavioral therapy (CBT) are recommended as safe and effective treatments for OCD. Despite being an effective non-pharmacological treatment, CBT has several drawbacks such as limited access to CBT therapists, high cost, and delayed clinical response [3]. SRIs are first-line pharmacologic treatment of OCD; however, only about half of the patients respond to SRI therapy
[4-6], and a considerable percentage show significant residual symptoms even after multiple trials of SRIs $[1,7,8]$. The practice guidelines for SRI-refractory patients generally include augmentation with antipsychotics [4]; however, patients often experience intolerable side effects [9]. This shows the importance of alternative approaches to OCD pharmacotherapy.

A variety of underlying mechanisms have been proposed in the development of OCD, such as disruption of serotonergic function and dopamine system [10], and more recently there is evidence on the role of glutamatergic system in OCD pathology [11]. Increased 
glutamate levels in cerebrospinal fluid, glutamatergic over-activity, and polymorphism of gene coding $\mathrm{N}$-methyl-D-aspartate (NMDA) receptor are shown to contribute to OCD occurrence [1114]. In addition, there is a large body of evidence on the clinical benefits of augmentation therapy with glutamate-modulating agents such as riluzole, $\mathrm{N}$-acetylcysteine, ketamine, and amantadine in reducing symptoms in SRI-refractory OCD [15-19].

Memantine is a non-competitive antagonist of NMDA receptor and is approved by the U.S. Food and Drug Administration for the treatment of Alzheimer's disease [12]. It is reported to be safe and well tolerated at doses as high as twice the dosage commonly prescribed for patients with Alzheimer's disease [20, 21]. Its most commonly reported side effects include dizziness, somnolence, confusion, and headache that are usually mild and transient [22, 23]. Although limited data on the off-label uses of memantine is available for various psychiatric disorders, reported results have mostly been promising [12]. There are a number of controlled trials that showed $5-20 \mathrm{mg} /$ day memantine augmentation in moderate to severe OCD patients was significantly effective in reducing symptom severity [24-27]. In a recent double-blind placebo-controlled trial by Ghaleiha et al., $89 \%$ remission was observed after 8 weeks of memantine augmentation against $32 \%$ from placebo [25]. Another double-blind placebo-controlled study by Haghighi et al. showed treatment response in $93 \%$ of patients receiving memantine augmentation against only $27 \%$ in the placebo group [24].

Only a few studies including 2 case reports, and an open-label trial assessed memantine augmentation in SRI-refractory OCD patients [28-30]. Aboujaoude et al. studied 15 OCD patients who had failed an average of 2.8 SRI trials; $40 \%$ had failed augmentation with atypical antipsychotics and more than half suffered from psychiatric comorbidities. Over a 12-week trial with $20 \mathrm{mg} /$ day memantine augmentation, $43 \%$ of patients achieved treatment response [30].

This study is the first double-blind randomized placebo-controlled trial that aims to assess the efficacy of memantine augmentation in SRI-refractory OCD patients with no psychiatric comorbidity. Given the safety and tolerability of memantine, the dose of $20 \mathrm{mg} /$ day was considered to achieve rapid relief of symptoms in refractory OCD patients.

\section{Methods}

\section{Study design}

A prospective double-blind randomized placebo-controlled trial was conducted on SRI-refractory OCD patients in Imam Khomeini Hospital in Ahvaz, Iran, from December 2015 to November 2016. Taking into account the trial's inclusion and exclusion criteria, recruited patients were randomized to 2 groups receiving either memantine in $10 \mathrm{mg}$ tablets (Alzantin, Sobhan Darou, Iran) or placebo twice a day for 12 weeks in addition to their existing SRI therapy. The placebo tablets were made in the School of Pharmacy, Ahvaz Jundishapur University of Medical Sciences, with the same appearance and packaging to those of memantine.

All patients were provided with written informed consent as well as full explanation of the protocol design. The consent form described the study, outlined the possible risks, and indicated that an experimental medication or placebo would be consumed daily. The protocol was approved by the ethics committee of Ahvaz Jundishapur University of Medical Sciences (identifier code: IR.AJUMS. REC.1394.314) and was conducted according to the Declaration of Helsinki. The trial was registered in the Iranian Registry of Clinical Trials (www.irct.ir, registration number: IRCT2015110324853N1).

\section{Yale-Brown Obsessive Compulsive Scale}

The Yale-Brown Obsessive Compulsive Scale (Y-BOCS) is commonly used in clinical studies to assess the severity of OCD and response to treatment [25, 26, 31]. It comprises 2 subscales including obsession and compulsion, each with 5 items rated from 0 (none) to 4 (extreme). The subscales' score range is hence $0-20$, and the total $\mathrm{Y}$-BOCS range is $0-40$. The $\mathrm{Y}$-BOCS is rated by clinicians and has proven validity and reliability for measuring OCD symptoms $[32,33]$. OCD severity is defined using Y-BOCS total score as extreme (score 32-40), severe (score 24-31), moderate (16-23), and mild (8-15) [33]. In the present study, the Y-BOCS was used to quantify the severity of $O C D$ and evaluate treatment response, defined as $\geq 35 \%$ reduction in Y-BOCS total score [34].

\section{Inclusion and exclusion criteria}

SRI-refractory OCD patients aged $18-40$ years with Y-BOCS $\geq 24$ (severe to extreme) were included. The diagnosis of OCD was based on the Diagnostic and Statistical Manual of Mental Disorders, Fifth Edition (DSM-5). SRI-refractory was defined as failing to at least 3 adequate trials of SRI therapy, 1 of which was clomipramine [7]. The adequate trial was considered as being stable for a minimum of 3 months at the maximum tolerated dose of an SRI therapy [35]. In addition, patients had to be stable on their existing SRI therapy for at least 3 months prior to admission to the study.

Patients with the following conditions were excluded: (1) receiving CBT at the time of enrollment; (2) additional anxiety disorder (such as panic disorder, post-traumatic stress disorder, general anxiety disorder); (3) mood disorder (major depressive disorder or bipolar disorder); (4) current drug or alcohol abuse or dependence; (5) any systemic disorder (such as diabetes, hypertension, hyper or hypothyroidism, severe renal or hepatic impairment); (6) a history of seizure; (7) pregnancy or breast-feeding; or (8) a history of memantine use.

\section{Sample size and statistical analysis}

Based on data from a previous trial of memantine in severe OCD patients [24], considering a power of $80 \%$ and alpha $=0.05$, and assuming an attrition rate of $20 \%$, a sample size of 32 (16 in each group) was calculated.

IBM SPSS version 21.0 (SPSS Inc., Chicago, IL, USA) was used for statistical analyses. A p-value of 0.05 was considered as significant. Categorical variables were reported as number (\%) and continuous variables as mean \pm standard deviation (SD). Demographic characteristics and baseline $\mathrm{Y}$-BOCS scores were compared between the memantine and placebo groups using t-test or chi-square, whichever was appropriate.

A mixed 4 (time) $\times 2$ (group) analysis of variance, with time as the within-subjects factor and group (memantine vs. placebo) as the between-subjects factor, was run for the Y-BOCS and its subscales. The homogeneity of variance was verified using Levene's 
test. Results of Greenhouse-Geisser correction were reported whenever Mauchly's sphericity test was significant. When the interaction between time $\times$ group was significant, post hoc analysis based on pairwise comparisons was conducted.

\section{Allocation, randomization, and blinding}

The participants were randomized to receive either memantine or placebo, in addition to their existing SRI therapy, using a simple computerized randomization program. Staff responsible for preparation of trial medications and randomization process were not further involved in the study. Throughout the study, all patients were visited by the same psychiatrist who rated Y-BOCS scores, prescribed the trial medications, and assessed the adverse effects. The patients, psychiatrist, and statistician were blind to allocation.

\section{Data collection}

All patients were visited at baseline and then every 4 weeks during the 12-week trial. At baseline, the following data were recorded for patients: age, sex, duration of illness, marital status, and past medical and drug history. The Y-BOCS total score and its 2 subscales (obsession and compulsion) were recorded at baseline and all subsequent visits. Adverse drug reactions were also assessed and recorded at each time point.

\section{Outcome measures}

The primary outcome was the change in the Y-BOCS from baseline to the end of trial in the 2 groups. The secondary outcome was defined as the number of individuals who achieved treatment response (Y-BOCS reduction $\geq 35 \%$ ) at the end of trial.

\section{Results}

\section{Patients' baseline characteristics}

A total of 58 SRI-refractory OCD patients were screened for eligibility in order to recruit 32 individuals who met the inclusion criteria. The patients were randomized into 2 groups of 16 , but 1 from each group withdrew from the study before the end of week 4 ( $\triangleright$ Fig. 1). The withdrawal cases did not report side effects or worsening of mental status as the cause of withdrawal. Among the remaining 30 patients aged between 18 and 40 (mean 30.7 \pm 5.7 ) years, 19 (63.3\%) were female and 17 (56.7\%) were married. Prior to enrolment, patients had received between 3 and 4 (mean $3.5 \pm 0.5$ ) adequate trials of SRI therapy including clomipramine and at least 2 selective serotonin reuptake inhibitors (SSRIs). At baseline, they had all been on a maximum tolerated dose of an SSRI for at least 12 weeks ( $\triangleright$ Table 1 ) and suffered from severe or extreme OCD with baseline Y-BOCS scores between 25 and 38 (mean $33.7 \pm 3.3) ; 23(76.7 \%)$ patients suffered from extreme and 7 $(23.3 \%)$ patients from severe OCD.

The baseline characteristics including demographic information, the type and dose of the concurrent SSRI regimen, and the mean YBOCS scores were not statistically different between the 2 groups ( $\triangleright$ Table 1). During the trial, patients did not participate in any CBT session and there was no alteration in patients' treatment regimen including dose change or initiation/discontinuation of medications.

\section{Y-BOCS total score}

- Table 2 shows that there was a significant difference across the 4 time points and between the 2 groups in the Y-BOCS total score.

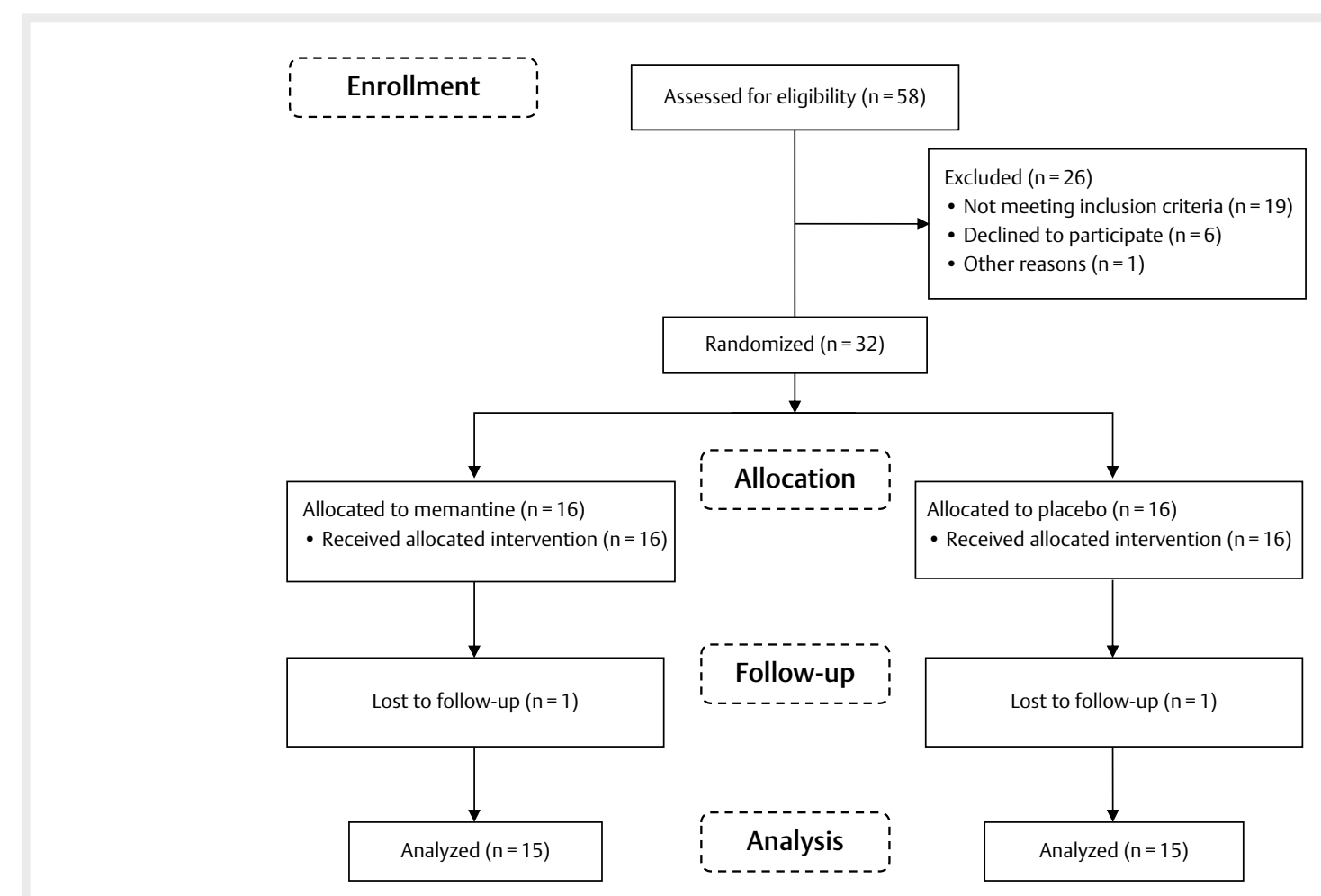

- Fig. 1 Randomization, treatment, and follow-up procedures. 
- Table 1 Baseline characteristics of patients.

\begin{tabular}{|c|c|c|c|c|}
\hline & \multicolumn{2}{|c|}{ Study groups } & \multicolumn{2}{|c|}{ p-value } \\
\hline & $\begin{array}{l}\text { Memantine group } \\
\quad(n=15)\end{array}$ & Placebo group $(n=15)$ & t-test & chi-square test \\
\hline Age (years), mean $\pm S D$ & $30.6 \pm 6.8$ & $30.7 \pm 4.7$ & 0.97 & \\
\hline Sex & & & & 0.70 \\
\hline Female & $9(60 \%)$ & $10(67 \%)$ & & \\
\hline Male & $6(40 \%)$ & $5(33 \%)$ & & \\
\hline Marital status & & & & 0.71 \\
\hline Single & $6(40 \%)$ & $7(47 \%)$ & & \\
\hline Married & $9(60 \%)$ & $8(53 \%)$ & & \\
\hline \multicolumn{5}{|l|}{$\mathrm{Y}-\mathrm{BCOS}$, mean $\pm \mathrm{SD}$} \\
\hline Obsession subscale & $17.0 \pm 2.8$ & $17.4 \pm 2.2$ & 0.67 & \\
\hline Compulsion subscale & $16.8 \pm 1.9$ & $16.0 \pm 2.2$ & 0.26 & \\
\hline Total score & $33.9 \pm 3.5$ & $33.4 \pm 3.2$ & 0.59 & \\
\hline Duration of illness (months), mean \pm SD & $20.5 \pm 4.6$ & $19.5 \pm 5.4$ & 0.57 & \\
\hline Concurrent SSRIs, dose range & & & & 0.98 \\
\hline Sertraline, $150-200 \mathrm{mg} /$ day & $2(13.3 \%)$ & $2(13.3 \%)$ & & \\
\hline Fluvoxamine, $200-300 \mathrm{mg} /$ day & $5(33.3 \%)$ & $6(40 \%)$ & & \\
\hline Citalopram, $60-80 \mathrm{mg} /$ day & $3(20 \%)$ & $3(20 \%)$ & & \\
\hline Fluoxetine, $70-80 \mathrm{mg} /$ day & $5(33.3 \%)$ & $4(26.6 \%)$ & & \\
\hline
\end{tabular}

- Table 2 Mean scores of Y-BOCS total and its obsession and compulsion subscales and results of statistical analyses.

\begin{tabular}{|c|c|c|c|c|}
\hline \multirow{2}{*}{$\begin{array}{l}\text { Score } \\
(\text { mean } \pm S D)\end{array}$} & \multirow[t]{2}{*}{ Time point } & \multicolumn{3}{|c|}{ Study groups } \\
\hline & & Memantine group & Placebo group & Statistics: mixed 4 (time) $\times 2$ (group) ANOVA \\
\hline \multirow[t]{4}{*}{ Y-BOCS total } & Baseline & $33.93 \pm 3.56$ & $33.47 \pm 3.29$ & Time: $F(2.1,57.9)=191.0, p<0.001, \eta^{2}=0.87(L)$ \\
\hline & Week 4 & $33.8 \pm 3.63$ & $33.67 \pm 3.22$ & Group: $F(1,28)=16.5, p<0.001, \eta^{2}=0.37(L)$ \\
\hline & Week 8 & $28.13 \pm 3.93$ & $33.67 \pm 2.92$ & Time $\times$ Group: $F(2.1,57.9)=189.8, p<0.001, \eta^{2}=0.87(L)$ \\
\hline & Week 12 & $20.00 \pm 2.56$ & $33.53 \pm 3.16$ & Greenhouse-Geisser epsilon $(\varepsilon)=0.69$ \\
\hline \multirow{4}{*}{$\begin{array}{l}\text { Y-BOCS } \\
\text { obsession } \\
\text { subscale }\end{array}$} & Baseline & $17.07 \pm 2.81$ & $17.46 \pm 2.26$ & Time: $F(2.2,61.8)=142.1, p<0.001, \eta^{2}=0.84(L)$ \\
\hline & Week 4 & $17.06 \pm 2.84$ & $17.40 \pm 2.26$ & Group: $F(1,28)=13.0, p=0.001, \eta^{2}=0.32(L)$ \\
\hline & Week 8 & $13.73 \pm 2.79$ & $17.26 \pm 2.09$ & Time $\times$ Group: $F(2.2,61.8)=129.7, p<0.001, \eta^{2}=0.82(L)$ \\
\hline & Week 12 & $9.33 \pm 1.91$ & $17.26 \pm 2.31$ & Greenhouse-Geisser epsilon $(\varepsilon)=0.74$ \\
\hline \multirow{4}{*}{$\begin{array}{l}\text { Y-BOCS } \\
\text { compulsion } \\
\text { subscale }\end{array}$} & Baseline & $16.87 \pm 1.92$ & $16.00 \pm 2.23$ & Time: $F(2.0,55.1)=56.8, p<0.001, \eta^{2}=0.67(L)$ \\
\hline & Week 4 & $16.60 \pm 1.68$ & $16.27 \pm 2.31$ & Group: $F(1,28)=6.9, p=0.014, \eta^{2}=0.20(L)$ \\
\hline & Week 8 & $14.27 \pm 1.94$ & $16.40 \pm 2.10$ & Time $\times$ Group: $F(2.0,55.1)=68.2, p<0.001, \eta^{2}=0.71(L)$ \\
\hline & Week 12 & $10.47 \pm 1.55$ & $16.40 \pm 2.13$ & Greenhouse-Geisser epsilon $(\varepsilon)=0.66$ \\
\hline
\end{tabular}

Most importantly, there was a significant interaction between time and group; hence, post hoc analyzes were conducted. It indicated that there was no significant difference in the $\mathrm{Y}$-BOCS total score between groups at baseline $(p=0.71)$ and at week $4(p=0.92)$. However, the difference between the 2 groups became significant at weeks 8 and 12 (both with $p<0.001$ ). The means of Y-BOCS total score reduction in the memantine and placebo groups were respectively $17.2 \%$ versus $-0.8 \%, p<0.001$, by week 8 and $40.9 \%$ versus $-0.3 \%, p<0.001$, by week 12 .

Considering the groups separately, the mean Y-BOCS total score did not change over time in the placebo group, but it decreased significantly in the memantine group from week 4 to week 8
(16.8\%) and then from week 8 to week 12 (28.5\%). D Fig. 2 shows the change in Y-BOCS total score for both groups across the 4 time points.

\section{Y-BOCS obsession and compulsion subscales}

As shown in $>$ Table 2, a similar trend was observed in the Y-BOCS subscales including obsession and compulsion scores. Having seen significant interaction between time and group in both subscales, the post hoc analysis showed that the difference in Y-BOCS subscales between the 2 groups was not significant at baseline and week 4 but became significant at weeks 8 and 12 ( $p$-values were $p<0.001)$. The means of $Y-B O C S$ obsession subscale reduction in 


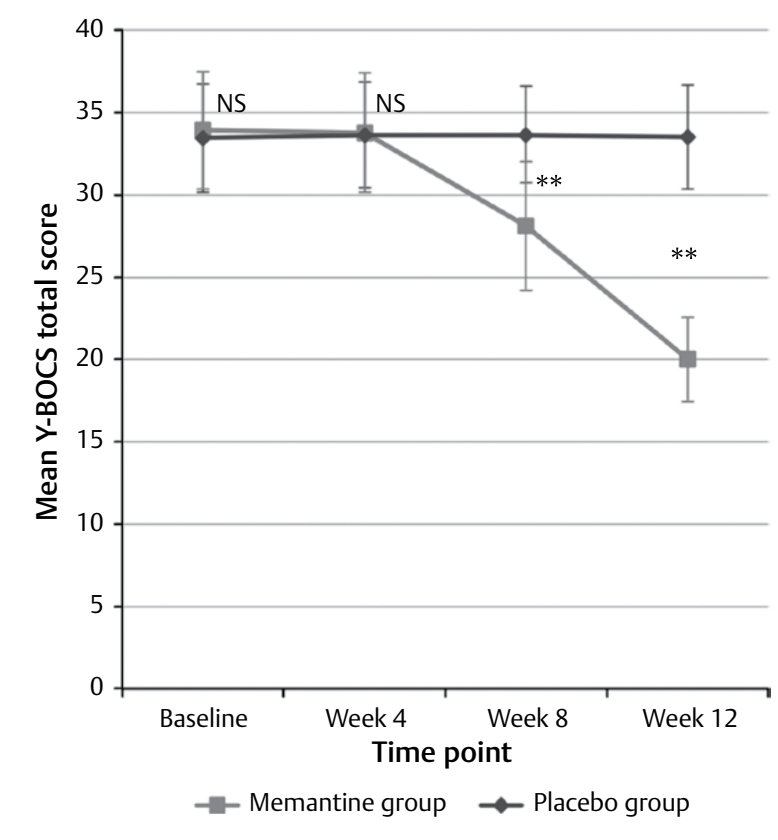

Fig. 2 Variation of mean Y-BOCS total score for both study groups across the four time points. NS: non-significant; ${ }^{*}{ }^{*} \mathrm{p} \leq 0.001$.

- Table 3 Reported adverse effects during the trial.

\begin{tabular}{|l|c|c|}
\hline Adverse effect & $\begin{array}{c}\text { Memantine } \\
\text { group }(\mathbf{n}=\mathbf{1 5})\end{array}$ & $\begin{array}{c}\text { Placebo group } \\
(\mathbf{n}=\mathbf{1 5})\end{array}$ \\
\hline Headache & $2(13.3 \%)$ & $1(6.6 \%)$ \\
\hline Constipation & $1(6.6 \%)$ & $3(20 \%)$ \\
\hline Nausea & $1(6.6 \%)$ & $1(6.6 \%)$ \\
\hline Dizziness & $2(13.3 \%)$ & $2(13.3 \%)$ \\
\hline Decreased appetite & $1(6.6 \%)$ & $1(6.6 \%)$ \\
\hline
\end{tabular}

the memantine and placebo groups were respectively $19.5 \%$ versus $0.88 \%, p<0.001$, by week 8 and $45.2 \%$ versus $1.1 \%, p<0.001$, by week 12 . The corresponding results in the compulsion subscale were respectively $15.2 \%$ versus $-2.9 \%, p<0.001$, by week 8 and $37.6 \%$ versus $-3.1 \%, p<0.001$, by week 12 .

\section{Treatment response}

By week 8, despite the significant reduction of Y-BOCS total scores in the memantine group (17.2\%), no patient in either of the groups met the criteria for treatment response. At the end of trial (i. e., week 12), however, treatment response was observed in 11 (73.3\%) patients. No patient in the placebo group met the criteria for treatment response by week 12 .

\section{Adverse effects}

There was no statistically significant difference between the 2 groups with respect to adverse effects $(p=0.87)$, as shown in - Table 3. Reported adverse effects were mild and transient and did not result in major discomfort. The 2 withdrawal cases were not due to adverse drug reaction.

\section{Discussion}

This study, to the best of the authors' knowledge, is the first randomized placebo-controlled trial of adjuvant $20 \mathrm{mg} /$ day memantine in SRI-refractory OCD patients. The key finding of the study was that adding memantine to the maximum tolerated dose of an SRI significantly improved OCD symptoms without causing increased side effects.

The assessment of patients at the end of week 4 showed no significant improvement in the Y-BOCS total score in either of the groups. However, by week 8 , a significant reduction in the mean $\mathrm{Y}$ BOCS score was observed in the memantine group, while the placebo group showed no improvement. Despite the noticeable $Y$ BOCS score reduction in the memantine group, no patient met the criteria for treatment response.

From week 8 to week 12, another significant reduction in the mean Y-BOCS score was seen in the memantine group that resulted in treatment response being achieved in $73.3 \%$ of patients. However, no improvement in the Y-BOCS score was observed in the placebo group by the end of week 12 , which was in fact expected given SRI-refractoriness of the patients recruited in the trial. The results showed that a time-to-effect of 8 weeks was necessary to observe significant improvement in OCD symptoms, while treatment response was only seen after 12 weeks of memantine augmentation.

The findings from the present study corroborate the results from previous studies on memantine augmentation for OCD patients. A double-blind placebo-controlled study by Haghighi et al. on severe OCD patients showed that low-dose (5-10 mg/day) memantine added to standard SRI monotherapy not only accelerated the response time, but also increased the overall response rate [24]. A considerable reduction in the mean Y-BOCS score was observed in the memantine group at weeks 8 and 12, resulting in a significantly higher response rate versus the placebo group (93\% vs. $27 \%$ ) at the end of week 12. Despite the title of study implies that refractory patients were assessed, it was actually stated in the discussion section that all recruited OCD patients were treated for the first time.

In a double-blind placebo-controlled study by Ghaleiha et al. on severe OCD patients, concomitant administration of memantine (20 mg/day) and fluvoxamine $(200 \mathrm{mg} /$ day) versus fluvoxamine monotherapy resulted in $100 \%$ treatment response in the former group against $32 \%$ in the latter group at the end of the 8 -week trial [25]. In addition, remission (i. e., Y-BOCS $\leq 16$ ) rate was $89 \%$ in the memantine against $32 \%$ in the placebo group. No patient in the present study achieved remission at the end of trial. The shorter time-to-effect and high remission rate reported by Ghaleiha et al. compared to the present study may well be due to the fact that the patients recruited by Ghaleiha et al. were not treatment-refractory.

In the only previous study on the effects of memantine augmentation in SRI-refractory OCD patients by Aboujaoude et al., treatment response was observed in $43 \%$ of patients receiving $20 \mathrm{mg} /$ day adjuvant memantine over a 12-week open-label trial. The patients had failed an average of $2.8 \pm 1.8 \mathrm{SRI}$ trials prior to admission to the study. The lower response rate compared to that of the present study may be due to the presence of patients with psychiatric comorbidities who were not excluded by Aboujaoude et al.

Given the safety and high tolerability of memantine, even at higher doses than those usually used in clinical practice [20], the 
starting dose of $20 \mathrm{mg} /$ day was considered for the current trial to achieve faster onset of action $[25,27,30]$. One notable finding from the present study was that using the starting dose of $20 \mathrm{mg} /$ day adjuvant memantine did not result in a higher rate of adverse effects. In all the previous studies mentioned above, the maintenance dose was reached by upward titration of $5 \mathrm{mg}$ per week to reduce the potential risk of adverse effects. Nevertheless, the present study showed that memantine dose titration may not be necessary in SRI-refractory OCD patients.

A limitation of the current study was that patients suffering from other concomitant psychiatric disorders were excluded. Although the effect of memantine in such patients remained unclear, for standard clinical trials it is common to include comorbidity-free populations. Another limitation was that the Y-BOCS was assessed every 4 weeks. Weekly assessments can help to determine timeto-effect more precisely. In addition, adverse effects were recorded at each visit by clinical interview and no formal psychometric measure was used. Despite the relatively small sample size, statistically significant results were obtained for both primary and secondary outcomes, which shows that the results would be applicable to larger population.

In conclusion, the results from the present clinical trial do support the limited evidence on the effectiveness of memantine as a safe and well-tolerated augmentation in the treatment of SRI-refractory OCD. Current treatment strategies such as higher doses of first-line therapies or antipsychotic augmentation need to be weighed against the potential side effect burden. The promising findings from this study on the efficacy of memantine augmentation in SRI-refractory OCD patients, in addition to its mild and transient side effects, opens interesting debate on exploring memantine monotherapy in OCD patients. Given the proven effectiveness of NMDA antagonists in OCD treatment, it is recommended that future studies may consider memantine as monotherapy in nonmedicated OCD patients.

Funding: This work was funded by a research grant from Ahvaz Jundishapur University of Medical Sciences in support of a Doctor of Pharmacy thesis by Setareh Razooghi (Grant number: GP94097).

\section{Conflict of Interest}

No conflict of interest has been declared by the author(s).

\section{References}

[1] Pittenger C, Kelmendi B, Bloch $M$ et al. Clinical treatment of obsessive compulsive disorder. Psychiatry (Edgmont) 2005; 2: 34-43

[2] Bruno A, Pandolfo G, Cedro C et al. Effect of ziprasidone augmentation of serotonin reuptake inhibitors in treatment-resistant obsessivecompulsive disorder: A 12-week, open-label uncontrolled preliminary study. Clin Neuropharmacol 2016; 39: 6-9

[3] Koran LM, Hanna GL, Hollander E et al. Practice guideline for the treatment of patients with obsessive-compulsive disorder. Am J Psychiatry 2007; 164: 5-53

[4] Kellner M. Drug treatment of obsessive-compulsive disorder. Dialogues Clin Neurosci 2010; 12: 187-197
[5] Mohammadi MR, Ghanizadeh A, Rahgozar M et al. Prevalence of obsessive-compulsive disorder in Iran. BMC Psychiatry 2004; 4: 2

[6] Pallanti S, Hollander E, Bienstock C et al. Treatment non-response in OCD: methodological issues and operational definitions. Int ] Neuropsychopharmacol 2002; 5: 181-191

[7] Atmaca M. Treatment-refractory obsessive compulsive disorder. Prog Neuropsychopharmacol Biol Psychiatry 2016; 70: 127-133

[8] Akyol Ardic U, Ercan ES, Kutlu A et al. Successful treatment response with aripiprazole augmentation of SSRIs in refractory obsessive-compulsive disorder in childhood. Child Psychiatry Hum Dev 2016 [Epub ahead of print]

[9] Veale D, Miles S, Smallcombe $\mathrm{N}$ et al. Atypical antipsychotic augmentation in SSRI treatment refractory obsessive-compulsive disorder: a systematic review and meta-analysis. BMC Psychiatry 2014; 14: 317

[10] Aouizerate B, Guehl D, Cuny E et al. Pathophysiology of obsessivecompulsive disorder: A necessary link between phenomenology, neuropsychology, imagery and physiology. Prog Neurobiol 2004; 72: $195-221$

[11] Albelda N, Bar-On N, Joel D. The role of NMDA receptors in the signal attenuation rat model of obsessive-compulsive disorder. Psychopharmacology (Berl) 2010; 210: 13-24

[12] Zdanys K, Tampi RR. A systematic review of off-label uses of memantine for psychiatric disorders. Prog Neuropsychopharmacol Biol Psychiatry 2008; 32: 1362-1374

[13] Arnold PD, Rosenberg DR, Mundo E et al. Association of a glutamate (NMDA) subunit receptor gene (GRIN2B) with obsessive-compulsive disorder: a preliminary study. Psychopharmacology (Berl) 2004; 174 : 530-538

[14] Paydary K, Akamaloo A, Ahmadipour A et al. N-acetylcysteine augmentation therapy for moderate-to-severe obsessive-compulsive disorder: randomized, double-blind, placebo-controlled trial. J Clin Pharm Ther. 2016; 41: 214-219

[15] Coric V, Taskiran S, Pittenger C et al. Riluzole augmentation in treatment-resistant obsessive-compulsive disorder: An open-label trial. Biol Psychiatry 2005; 58: 424-428

[16] Afshar H, Roohafza H, Mohammad-Beigi $\mathrm{H}$ et al. N-acetylcysteine add-on treatment in refractory obsessive-compulsive disorder: $\mathrm{A}$ randomized, double-blind, placebo-controlled trial. J Clin Psychopharmacol 2012; 32: 797-803

[17] Bloch MH, Wasylink S, Landeros-Weisenberger A et al. Effects of ketamine in treatment-refractory obsessive-compulsive disorder. Biol Psychiatry 2012; 72: 964-970

[18] Stryjer R, Budnik D, Ebert T et al. Amantadine augmentation therapy for obsessive compulsive patients resistant to SSRIs-an open-label study. Clin Neuropharmacol 2014; 37: 79-81

[19] Lafleur DL, Pittenger C, Kelmendi B et al. N-acetylcysteine augmentation in serotonin reuptake inhibitor refractory obsessive-compulsive disorder. Psychopharmacology (Berl) 2006; 184: 254-256

[20] Ferguson JM, Shingleton RN. An open-label, flexible-dose study of memantine in major depressive disorder. Clin Neuropharmacol 2007; 30: $136-144$

[21] Keck PE Jr., Hsu HA, Papadakis K et al. Memantine efficacy and safety in patients with acute mania associated with bipolar I disorder: A pilot evaluation. Clin Neuropharmacol 2009; 32: 199-204

[22] Amidfar M, Khiabany M, Kohi A et al. Effect of memantine combination therapy on symptoms in patients with moderate-to-severe depressive disorder: Randomized, double-blind, placebo-controlled study. J Clin Pharm Ther 2017; 42: 44-50

[23] Wu K, Hanna GL, Rosenberg DR et al. The role of glutamate signaling in the pathogenesis and treatment of obsessive-compulsive disorder. Pharmacol Biochem Behav 2012; 100: 726-735 
[24] Haghighi M, Jahangard L, Mohammad-Beigi $\mathrm{H}$ et al. In a double-blind, randomized and placebo-controlled trial, adjuvant memantine improved symptoms in inpatients suffering from refractory obsessivecompulsive disorders (OCD). Psychopharmacology (Berl) 2013; 228: 633-640

[25] Ghaleiha A, Entezari N, Modabbernia A et al. Memantine add-on in moderate to severe obsessive-compulsive disorder: randomized double-blind placebo-controlled study. J Psychiatr Res 2013; 47: 175-180

[26] Stewart SE, Jenike EA, Hezel DM et al. A single-blinded case-control study of memantine in severe obsessive-compulsive disorder. J Clin Psychopharmacol 2010; 30: 34-39

[27] Sahraian A, Jahromi LR, Ghanizadeh A et al. Memantine as an adjuvant treatment for obsessive compulsive symptoms in manic phase of bipolar disorder: A randomized, double-blind, placebo-controlled Clinical Trial. J Clin Psychopharmacol 2017; 37: 246-249

[28] Pasquini M, Biondi M. Memantine augmentation for refractory obsessive-compulsive disorder. Prog Neuropsychopharmacol Biol Psychiatry 2006; 30: 1173-1175

[29] Poyurovsky M, Weizman R, Weizman A et al. Memantine for treatment-resistant OCD. Am J Psychiatry 2005; 162: 2191-2192
[30] Aboujaoude E, Barry J], Gamel N. Memantine augmentation in treatment-resistant obsessive-compulsive disorder: An open-label trial. J Clin Psychopharmacol 2009; 29: 51-55

[31] Feusner JD, Kerwin L, Saxena S et al. Differential efficacy of memantine for obsessive-compulsive disorder vs. generalized anxiety disorder: an open-label trial. Psychopharmacol Bull 2009; 42: 81-93

[32] Goodman WK, Price LH, Rasmussen SA et al. The Yale-brown obsessive compulsive scale. II. validity. Arch Gen Psychiatry 1989; 46: 10121016

[33] Goodman WK, Price LH, Rasmussen SA et al. The Yale-brown obsessive compulsive scale. I. development, use, and reliability. Arch Gen Psychiatry 1989; 46: 1006-1011

[34] Pallanti S, Quercioli L. Treatment-refractory obsessive-compulsive disorder: methodological issues, operational definitions and therapeutic lines. Prog Neuropsychopharmacol Biol Psychiatry 2006; 30: $400-412$

[35] Jenike MA, Rauch SL. Managing the patient with treatment-resistant obsessive compulsive disorder: Current strategies. J Clin Psychiatry 1994; 55 (Suppl): 11-17 